\title{
Child Maltreatment and Later Cognitive Functioning: A Systematic Review
}

\author{
Maus-Tratos na Infância e Funcionamento Cognitivo Tardio: \\ Uma Revisão Sistemática
}

\author{
Tatiana Quarti Irigaray*, ${ }^{a}$, Janaína Barbosa Pacheco ${ }^{b}$, Rodrigo Grassi-Oliveira ${ }^{a}$, \\ Rochele Paz Fonseca ${ }^{a}$, José Carlos de Carvalho Leite ${ }^{c} \&$ Christian Haag Kristensen ${ }^{a}$ \\ ${ }^{a}$ Pontifícia Universidade Católica do Rio Grande do Sul, Porto Alegre, Brasil, \\ ${ }^{b}$ Universidade Federal de Ciências da Saúde de Porto Alegre, Porto Alegre, Brasil \\ $\&{ }^{c}$ Centro Universitário La Salle, Canoas, Brasil
}

\begin{abstract}
This systematic review sought to assess the impact of child maltreatment on cognitive functioning. Seventeen papers from Medline, PsycINFO, Embase and Amed (1995-2011) databases were analyzed based on inclusion/exclusion criteria. The studies have shown that maltreatment during childhood has deleterious effects on cognitive functioning. Overall, adults or children/teenagers exposed to abuse during childhood performed poorly on tasks meant to assess verbal episodic memory, working memory, attention, and executive functions. We conclude that child maltreatment is a risk factor for short and long-term development due to potential adverse effects on cognitive functioning. Keywords: Maltreatment, cognitive function, child, memory, executive functions.

Resumo

Este estudo buscou investigar os efeitos da exposição a maus-tratos sobre o funcionamento cognitivo através do método de revisão sistemática da literatura. Pelos bancos de dados Medline, PsycINFO, Embase e Amed (1995-2011), a partir de critérios de inclusão/exclusão, foram recuperados e analisados 17 trabalhos.Os estudos mostraram que há um efeito deletério de experiências de maus-tratos na infância no funcionamento cognitivo. De maneira geral, adultos ou crianças/adolescentes que sofreram maus-tratos na infância demonstraram um perfil cognitivo inferior em tarefas que examinaram memória verbal episódica, memória de trabalho, atenção e componentes das funções executivas. Conclui-se que maus-tratos sofridos na infância constituem fatores de risco para o desenvolvimento, tanto a curto quanto a longo-prazo, pois podem acarretar prejuízos cognitivos.

Palavras-chave: Maus tratos, funcionamento cognitivo, memória, funções executivas.
\end{abstract}

In its broadest sense, cognition may be defined as a set of mental abilities that enable acquisition, storage, transformation, and use of knowledge. From a theoretical standpoint, cognition comprises a set of functions distinguished both by the type of information processed and addressed (visual, verbal, mixed - distinguishing oral vs. written language, visual vs. auditory perception, and so on) and by the type or specificity of cognitive activity, each of which corresponds to different psychological processes (attention, memory, numeracy; Ska et al., 2009).

Studies show that cognitive impairment may be associated with maltreatment during childhood (Beers \& De

* Endereço para correspondência: Pontifícia Universidade Católica do Rio Grande do Sul, Av. Ipiranga, 6681, Partenon, Porto Alegre, RS, Brasil 90619-900. E-mail: tatiana.irigaray@superig.com.br, janainapacheco@uol. com.br, rodrigo.grassi@pucrs.br, rochele.fonseca@pucrs. br, jcdc.leite@googlemail.com e christian.kristensen@pucrs.br This research was supported by Coordenação de Aperfeiçoamento de Pessoal de Nível Superior (CAPES).
Bellis, 2002; Bremner et al., 1995; De Bellis, Hooper, Spratt, \& Woolley, 2009; Goodman, Quas, \& Ogle, 2010; Mezzacappa, Kindlon, \& Earls, 2001; Savitz, van der Merwe, Stein, Solms, \& Ramesar, 2007). Maltreatment can be defined as any form of childhood and adolescent victimization, particularly sexual and physical abuse (Briere, 1997; McLeer, Deblinger, Henry, \& Orvaschel, 1992; Pynoos, 1992; Weinstein, Staffelbach, \& Biaggio, 2000). The construct of maltreatment used in the present study is based on the factors described by Bernstein et al. (1994; Bernstein et al., 2003), and includes traumatic experiences involving physical abuse, emotional abuse, sexual abuse, and emotional and/or physical neglect.

According to Bernstein et al. (2003), physical abuse refers to bodily assaults on a child by an older person that pose a risk of, or result in, injury. Emotional abuse refers to verbal assaults on the child's sense of worth or well-being, or any humiliating, demeaning, or threatening behavior directed toward the child. Sexual abuse refers to sexual 
contact or conduct between a child and an older person, including assault if the child resists, or inappropriate touching or fondling with sexual intent. Physical neglect is defined as the failure of caregivers to ensure that a child's basic needs, such as food, shelter, clothing, safety, and health, are met. Lack of parental supervision also constitutes physical neglect if it places the child at risk. Finally, emotional neglect refers to the failure of caretakers to provide a child's basic psychological and emotional needs, such as love, encouragement, belonging, and support.

According to Briere and Elliott (2003), there is no consensus as to the estimated prevalence of child maltreatment. Possible reasons for the wide variability of prevalence estimates include different definitions of maltreatment, use of different research methods, and varying representativeness of studied samples. In a U.S. study of physical and sexual abuse in a sample of 1,442 adults, the prevalence of sexual abuse was determined as $14.2 \%$ among men and $32.3 \%$ among women; $22.2 \%$ of men and $19.5 \%$ of women reported having been physically abused during childhood (Briere \& Elliott, 2003). Another U.S. study, carried out on a sample of 15,197 young adults, found neglect to be the most prevalent form of maltreatment (41.5\%), followed by physical abuse (28.4\%); sexual abuse was least prevalent, accounting for $4.5 \%$ of cases (Hussey, Chang, \& Kotch, 2006).

MacMillan et al. (1997) assessed 9,953 subjects aged 15 years or older in Ontario, Canada, and found the prevalence of physical maltreatment to be $31.2 \%$ in men and $21.1 \%$ in women. Childhood sexual abuse was reported by more women (12.8\%) than men (4.3\%). A study of 2,869 young adults in the United Kingdom found the overall prevalence of maltreatment to be $16 \%$. Sexual abuse was experienced by $11 \%$ of participants, followed by physical abuse (7\%), emotional abuse $(6 \%)$, absence of care $(6 \%)$, and absence of supervision (5\%; May-Chahal \& Cawson, 2005).

In Brazil, studies on the prevalence of child maltreatment are scarce. Brito, Zanetta, Mendonça, Barison, and Andrade (2005) assessed the frequency of domestic violence against children by means of interviews with 150 families in the municipality of São José do Rio Preto, São Paulo. Physical violence was the most prevalent form of maltreatment, experienced in $58 \%$ of analyzed cases. Neglect and psychological abuse were experienced by $34.5 \%$ of subjects, and sexual abuse, by $29 \%$. Psychological violence was least prevalent, accounting for only $14 \%$ of cases. Another Brazilian study calculated the prevalence rate of child maltreatment as $5.7 \%$, on the basis of information provided by the educational sector; neglect was the most common form of maltreatment in this sample (Faleiros, Matias, \& Bazon, 2009).

The association between maltreatment and cognitive development has been systematically investigated throughout the life cycle (De Bellis, Hooper, \& Sapia, 2005). For instance, studies suggest that chronic abuse and neglect in childhood have a devastating effect on brain maturation and organization processes (Bremner, 1999;
De Bellis, 2005; Glaser, 2000), including functional and structural changes in childhood, adolescence, and adulthood (Grassi-Oliveira, Ashy, \& Stein, 2008). Child maltreatment can lead to specific deficits in short-term verbal memory (Bremner et al., 1995), visual memory (Savitz et al., 2007), executive functions (Mezzacappa et al., 2001), and sustained attention (Beers \& De Bellis, 2002). Child maltreatment may also be associated with global cognitive deficits, including impaired intelligence, poor academic performance, and memory and learning disabilities (De Bellis et al., 2009; Goodman et al., 2010). Children with a history of abuse and post-traumatic stress disorder (PTSD) perform poorly on measures of attention and executive function (Beers \& De Bellis, 2002). Although evidence is mounting on the effects of traumatic events on children, adolescents, and adults, there is little information on their effect in older persons. Most studies on the developmental effects of trauma in older persons have been restricted to survivors of imprisonment or captivity during wartime (Yehuda, Stavitsky, Tischler, Golier, \& Harvey, 2005).

Child maltreatment constitutes a major public health and social welfare issue, as it has adverse long-term consequences that will affect the child throughout his or her life cycle, as well as the child's family and society at large (Brito et al., 2005; Gilbert et al., 2009). Exposure to maltreatment in childhood is also associated with psychological consequences. Studies have demonstrated a relationship between the experience of child maltreatment and later substance abuse, mental disorders (depression, anxiety, suicide), high-risk sexual behavior, obesity, and criminality, which persist throughout adulthood (Dube et al., 2003; Gilbert et al., 2009; Johnson et al., 2002; Mullen, Martin, Anderson, Romans, \& Herbison, 1996).

Child maltreatment has also been singled out as one of many factors that can affect academic performance (Kendall-Tackett \& Eckenrode, 1996; Kurtz, Gaudin, Wodarski, \& Howing, 1993; Rowe, \& Eckenrode, 1999; Shonk, \& Cicchetti, 2001). Studies show that maltreated children have poorer educational attainment and are more likely to require special education as compared with children who have no history of maltreatment (Boden, Horwood, \& Fergunsson, 2007; Lansford et al., 2002). Furthermore, children exposed to physical abuse and neglect tend to score poorly on reading and math tests, be more likely to repeat a grade, receive lower grades, and exhibit a greater incidence of discipline problems than children not exposed to abuse (Eckenrode, Laird, \& Doris, 1993). Strathearn, Gray, O'Callaghan and Wood (2001) found neglectful parental supervision during childhood to be associated with significantly lower intellectual development, persistently low IQ, and poor academic performance during adulthood.

The objective of this study is to investigate the association between exposure to maltreatment in childhood and later cognitive functioning. Toward that end, we shall review the existing literature on this topic, with a focus on empirical studies that compare exposed to nonexposed individuals. 


\section{Method}

The MEDLINE, PsycINFO, Embase, and Amed (through Ovid) were searched using various key words and MeSH (Medical Subject Headings) identifiers. The key words used were: maltreatment (or "sexual abuse", "psychological abuse", "physhical abuse", "child neglect", "treatment neglect", "sexual aggression", "psychological aggression", "physical aggression", "intentional injury") and cognition (or "awareness", "cognitive dissonance", "consciousness", "neuropsychology", "cognitive functions", "temporal orientation", "spatial orientation", "perception", "memory", "arithmetic skills", "language", "praxis", "executive functions") and child (or "human development", "child development", "childhood", "children", "infant", "infancy"). Searches were limited to English-language empirical studies, carried out on human subjects, and published in peer-reviewed journals, for which abstracts and references were available. Qualitative studies were excluded from the sample, as were duplicate articles. Searches were not restricted to any timeframe.

All studies selected for this systematic review were identified with the above search strategy. The aforementioned search strings yielded 404 abstracts, published between 1995 and 2011, from the MEDLINE, PsycINFO, Embase, and Amed databases. Each abstract was analyzed by two independent examiners according to the following criteria for inclusion: (a) empirical investigation of the effects of child maltreatment on cognitive functioning; (b) cross-sectional, case-control, randomized clinical trial, or cohort design; and (c) presence of a control group composed of individuals who were not exposed to maltreatment during childhood. A control group was required so as to limit the review to studies with a higher level of evidence quality. For the purposes of this systematic review, the independent variable child maltreatment was defined according to Bernstein et al. (1994; Bernstein et al., 2003), and thus includes traumatic experiences involving physical abuse, emotional abuse, sexual abuse, emotional neglect, and physical neglect.

Application of the criteria for inclusion narrowed the initial sample down to 22 abstracts. The full text of the corresponding articles was analyzed, and nine studies were excluded for failure to meet the objectives of the present study. In an attempt to extend the sample, the references of all selected articles were analyzed; this strategy yielded seven new studies of interest, two of which met the criteria for inclusion. After analysis by three experts, a further four articles were recommended for inclusion. Two of these four met the criteria for inclusion and were added to the sample. The Figure 1 shows the flowchart of the systematic review performed in this study.

\section{Results}

The present systematic review included a total of 17 articles. All selected studies used an experimental group
(EG, subjects exposed to some form of maltreatment) and a control group (CG, individuals not exposed to maltreatment). The selected studies were published between 1995 and 2011. Of the 17 studies included in the review, 16 used a case-control design and one was cross-sectional. Six studies (35.3\%) assessed a total of 853 children and/ or adolescents between the ages of 3.6 and 17.9. These participants were distributed evenly in terms of gender, with $424(49.7 \%)$ male children and/or adolescents and 429 (50.3\%) female children and/or adolescents in the sample. The eleven remaining studies assessed a total of 487 adults, 380 of whom (78.0\%) were women and 107 $(22.0 \%)$ were men. The ages of adult participants ranged from 18 to 56 .

Eight studies (47\%) evaluated the effects of sexual abuse on cognition (Bremner, Vermetten, Afzal, \& Vythilingam, 2004; Bremner et al., 2003; De Bellis, Hooper, Wooley, \& Shenk, 2010; Lysaker, Meyer, Evans, \& Marks, 2001; Navalta, Polcari, Webster, Boghossian, \& Teicher, 2006; Porter, Lawson, \& Bigler, 2005; Stein, Hanna, Vaerum, \& Koverola, 1999; Stein, Koverola, Hanna, Torchia, $\&$ McClarty, 1997). De Bellis et al. (2010) also studied the effects of general maltreatment. Four focused on neglect instead; Grassi-Oliveira et al. (2008) specifically investigated physical neglect and Grassi-Oliveira, Gomes, and Stein (2011) specifically investigated the consequences of childhood emocional neglect, whereas the two remaining studies (De Bellis et al., 2009; Nolin \& Ethier, 2007) did not specify type of neglect. Nolin and Ethier (2007), in addition to studying the effects of neglect as a single variable, also analyzed the role of neglect when associated with physical abuse. Hence, two studies analyzed the effects of more than one form of maltreatment: sexual abuse and physical abuse (Bremner et al., 1995) and neglect and physical abuse (Nolin \& Ethier, 2007). Beers and De Bellis (2002) and Shannon et al. (2011) studied maltreatment as an umbrella variable that included sexual abuse, physical abuse, emotional abuse, emotional neglect and witnessing domestic violence during childhood. Choi, Jeong, Rohan, Polcari, and Teicher (2009) assessed the effects of verbal abuse on cognition.

As shown in Table 1, the selected studies used several assessment instruments and analyzed more than one aspect of cognition. The most often studied cognitive functions were verbal episodic memory and learning capacity, followed by intelligence, attention, executive functions, visual memory, language and working memory. A wide variety of instruments were used to assess cognitive functioning in individuals subjected to child maltreatment. The most widely used instruments were subtests of the Wechsler Intelligence Scale, the California Verbal Learning Test, the Wechsler Memory Scale, the Wisconsin Card Sorting Test, the Trail Making Test, and the NEPSY battery of neuropsychological assessment tests for children. 
Irigaray, T. Q., Pacheco, J. B., Grassi-Oliveira, R., Fonseca, R. P., Leite, J. C. C. \& Kristensen, C. H. (2013). Child Maltreatment and Later Cognitive Functioning: A Systematic Review.

MEDLINE, PsycINFO, Embase, and Amed (Ovid) search using the terms "maltreatment", "cognition", "child*”, and MeSH headings

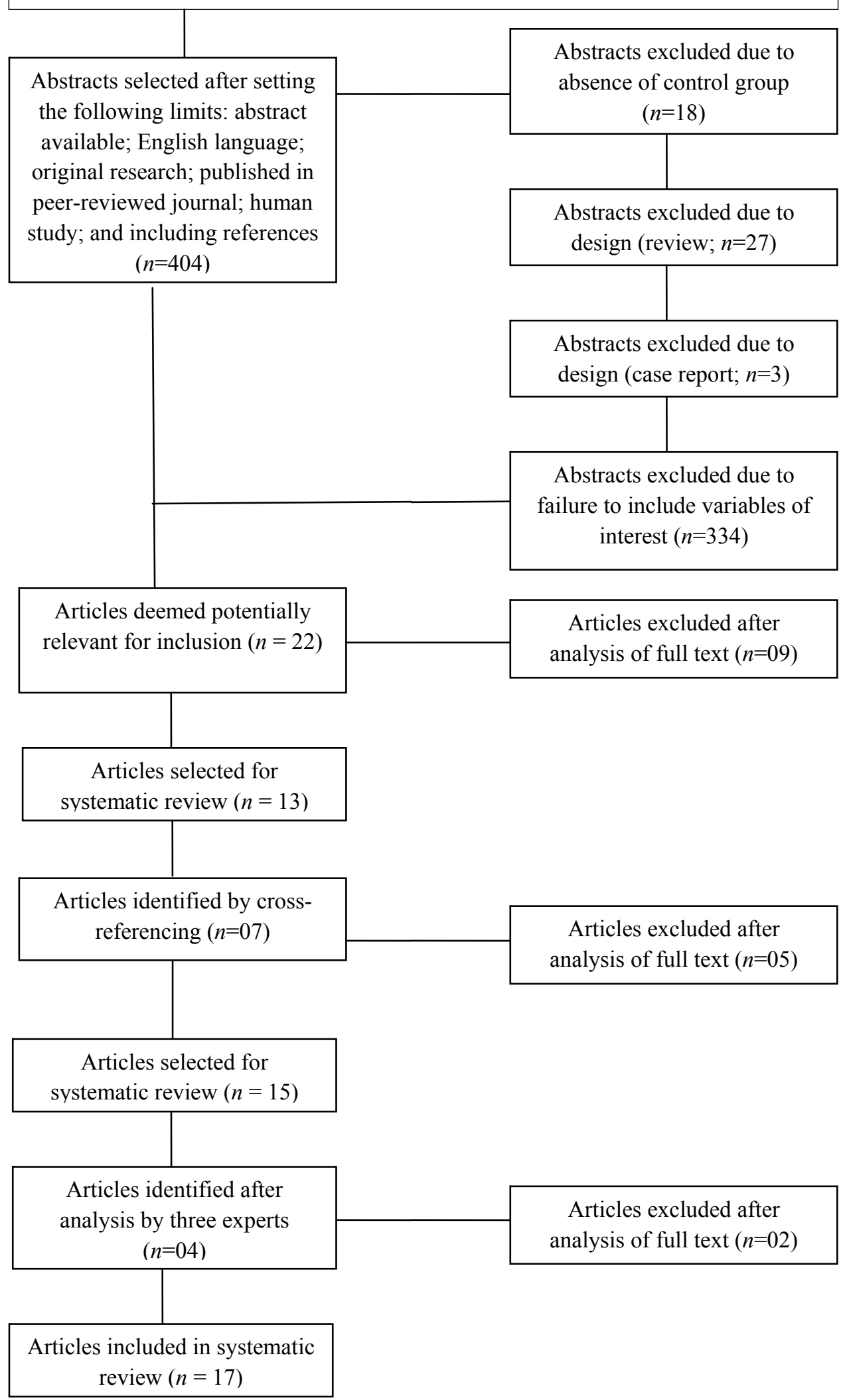

Figure 1. Article selection flowchart. 
Table 1

Description of Selected Studies, Including Sample Size, Participant Age, Instruments Used for Assessment of Cognitive Function, and Main Findings

\begin{tabular}{|c|c|c|c|}
\hline Author (year) & $\begin{array}{l}\text { Sample size } \\
\text { Age }( \pm S D)\end{array}$ & Assessment of cognitive function & Main findings \\
\hline
\end{tabular}

Adult studies

Bremner et al. $\quad N=41$

(1995)

$\mathrm{EG}=39.7$ (7.1)

$\mathrm{CG}=36.7(10.0)$

$\begin{array}{ll}\text { Stein et al. } & N=42 \\ (1997) & \mathrm{EG}=32.0(6.3) \\ & \mathrm{CG}=30.2(6.4)\end{array}$

Stein et al. $\quad N=42$

(1999) $\quad \mathrm{EG}=32.6(6.0)$

$\mathrm{CG}=29.5$ (6.1)

Lysaker et al. $\quad N=43$

(2001) $\mathrm{M}=45$ years

Bremner et al. $\quad N=33$

(2003) $\quad \mathrm{EG} 1=35(6.0)$

$\mathrm{EG} 2=32(8.0)$

$\mathrm{CG}=38$ (7.0)

$\begin{array}{ll}\text { Bremner et al. } & N=43 \\ (2004) & \mathrm{EG} 1=34(6.0) \\ & \mathrm{EG} 2=32(8.0) \\ & \mathrm{CG}=32(9.0)\end{array}$

Navalta et al. $\quad N=45$

(2006) $\quad \mathrm{EG}=20.0$

$\mathrm{CG}=19.4$

Grassi-Oliveira $\quad N=49$

et al. (2008) $\quad \mathrm{EG1}=39.3(9.3)$

$\mathrm{EG} 2=39.5$ (7.9)

$\mathrm{CG}=36.5$ (6.3)
WMS-R (verbal*), WMS-R

(visual); Verbal Selective

Reminding Test*; Visual and

Verbal Selective Reminding

Test*; WAIS-R (Arithmetic,

Vocabulary, Block Design, Picture

Arrangement)

WAIS-R (Vocabulary, Similarities, Picture Completion, Block

Design, Digit Span, Digit

Symbol); CVLT

CVLT; Benton Visual Retention

Task; TMT (A and B); WAIS-R

(Vocabulary, Digit Symbol,

Similarities, Picture Completion, Block Design, Digit Span)

WCST*; WAIS-III (Letter-

Number Sequencing*, Digit

Symbol Symbol*, Vocabulary);

CVLT

Verbal declarative memory task

WAIS-R (Vocabulary, Block

Design, Arithmetic, Picture

Arrangement); WMS-R (verbal*);

WMS-R (visual)

MAS (Visual span)*; GO/NOGO/STOP*

WMS-R (verbal*)
The EG (history of physical and sexual abuse in childhood) scored significantly lower than the CG on verbal episodic memory tasks (immediate and delayed recall).

There were no significant between-group differences in intellectual functioning or verbal episodic memory.

There were no significant between-group differences in verbal episodic memory (immediate and delayed recall), visual memory, attention, or executive function.

Participants with a history of sexual abuse in childhood had significantly lower executive function, working memory, and information processing speed scores.

There were no significant differences between EG1 (history of sexual abuse in childhood and posttraumatic stress disorder), EG2 (history of sexual abuse in childhood, but no posttraumatic stress disorder), or the CG on a verbal declarative memory task.

EG1 (history of sexual abuse in childhood and posttraumatic stress disorder) had significantly lower verbal episodic memory scores as compared to EG2 (history of sexual abuse in childhood, but no posttraumatic stress disorder) and the CG.

The EG (history of sexual abuse in childhood) had significantly lower memory and inhibitory capacity scores as compared to the CG.

EG1 (history of physical neglect and major depressive disorder) subjects scored significantly lower on verbal episodic memory (immediate and delayed recall) tasks as compared to EG2 (major depressive disorder but no history of neglect) and CG (no history of neglect and no major depressive disorder). 
Irigaray, T. Q., Pacheco, J. B., Grassi-Oliveira, R., Fonseca, R. P., Leite, J. C. C. \& Kristensen, C. H. (2013). Child Maltreatment and Later Cognitive Functioning: A Systematic Review.

\begin{tabular}{|c|c|c|c|}
\hline Author (year) & $\begin{array}{l}\text { Sample size } \\
\text { Age }( \pm S D)\end{array}$ & Assessment of cognitive function & Main findings \\
\hline $\begin{array}{l}\text { Choi et al. } \\
\text { (2009) }\end{array}$ & $\begin{array}{l}N=32 \\
\mathrm{EG}=21.9(2.4) \\
\mathrm{CG}=21.0(1.6)\end{array}$ & $\begin{array}{l}\text { WAIS-III (Verbal IQ and Verbal } \\
\text { Comprehension Index) }\end{array}$ & $\begin{array}{l}\text { There were no significant between- } \\
\text { group differences in verbal IQ and verbal } \\
\text { comprehension índex scores. }\end{array}$ \\
\hline $\begin{array}{l}\text { Shannon et al. } \\
\text { (2011) }\end{array}$ & $\begin{array}{l}N=85 \\
\mathrm{M}=41.1 \text { years } \\
(11.7)\end{array}$ & $\begin{array}{l}\text { NART; WMS-III (logical } \\
\text { memory*, word lists*, letter- } \\
\text { number sequencing*). }\end{array}$ & $\begin{array}{l}\text { The EG (history of childhood trauma and } \\
\text { schizophrenia) had significantly lower verbal } \\
\text { episodic memory (immediate and delayed } \\
\text { recall) and working memory scores as } \\
\text { compared to the CG. The EG outperformed } \\
\text { the CG in a word list recognition task. }\end{array}$ \\
\hline $\begin{array}{l}\text { Grassi-Oliveira } \\
\text { et al. (2011) }\end{array}$ & $\begin{array}{l}N=42 \\
\mathrm{EG}_{1}=39.6(10.4) \\
\mathrm{EG}_{2}=42.0(8.0) \\
\mathrm{CG}=10(6.1)\end{array}$ & $\begin{array}{l}\text { Brazilian version of the DRM } \\
\text { (Word list the DRM targets*) }\end{array}$ & $\begin{array}{l}\text { There were no differences between } \mathrm{EG}_{1}, \mathrm{EG}_{2} \text {, } \\
\text { and } \mathrm{CG} \text { in false and true memory scores. } \\
\mathrm{EG}_{1} \text { subjects (major depressive disorder and } \\
\text { history of emotional neglect) were less likely } \\
\text { to produce false memories than those in } \mathrm{EG}_{2} \\
\text { (major depressive disorder but no history of } \\
\text { emotional neglect) or the CG. There were no } \\
\text { differences in false item recall between } \mathrm{EG}_{2} \\
\text { and the CG. }\end{array}$ \\
\hline
\end{tabular}

Child/

adolescent

studies

Beers \& De $\quad N=29$

Bellis (2002)

$\mathrm{EG}=11.38(2.60)$

$\mathrm{CG}=12.17(1.75)$

WISC-III (Vocabulary, Digit

The EG (history of maltreatment and Span, Similarities*, Block Design, posttraumatic stress disorder) exhibited Object Assembly, Coding); significantly lower attention, executive Stroop Color and Word Test*; Digit Vigilance Test*; WCST*; COWAT*; TMT part B; CVLT; Rey-Osterrieth Complex Figure Test*; Money Road Map; Judgment of line orientation*; Grooved Pegboard Test.

Porter et al. $\quad N=48$ (2005) 8-14 years

WISC-III: Verbal IQ*; TOMAL* function and visuospatial function scores as compared to the $\mathrm{CG}$.

$\begin{array}{ll}\begin{array}{l}\text { Nolin \& Ethier } \\ \text { (2007) }\end{array} & N=137 \\ & (6-11 \text { years }) \\ & \text { EG1 }=9.3(2.0) \\ & \text { EG2 }=8.7(1.9) \\ & \text { CG }=8.8(1.8)\end{array}$

Purdue Pegboard (motor performance)*, NEPSY (Visual Attention, Auditory Attention and Response Set*, Comprehension of Instructions, Verbal Fluency, Tower*, Knock and Tap, Statue); CVLT; VMI*; WISC-III (Picture Completion, Block Design, Similarities*, Arithmetic*).
The EG (history of sexual abuse in childhood) scored significantly lower on verbal IQ and attention and concentration tasks as compared to the CG.

EG1 (history of neglect and physical abuse) scored significantly lower on manual dexterity, attention, visual-motor integration, arithmetic, and concept learning as compared to the CG. EG2 (history of neglect but no physical abuse) scored significantly lower on manual dexterity, attention, and visual-motor integration tasks as compared to the CG. 


\begin{tabular}{|c|c|c|c|}
\hline Author (year) & $\begin{array}{l}\text { Sample size } \\
\text { Age }( \pm S D)\end{array}$ & Assessment of cognitive function & Main findings \\
\hline $\begin{array}{l}\text { De Bellis et al. } \\
(2009)\end{array}$ & $\begin{array}{l}N=106 \\
\mathrm{EG} 1=8.30(2.2) \\
\mathrm{EG} 2=7.19(2.4) \\
\mathrm{CG}=7.77(1.8)\end{array}$ & $\begin{array}{l}\text { NEPSY (Fine motor: Fingertip } \\
\text { Tapping, Imitative Hand } \\
\text { Movements, Visuomotor } \\
\text { Precision; Language: } \\
\text { Phonological Processing, Speeded } \\
\text { Naming*, Comprehension*; } \\
\text { Visual-Spatial: Design Copying*, } \\
\text { Arrows, Block Construction*; } \\
\text { Memory/Learning: Memory for } \\
\text { Faces*, Memory for Names*, } \\
\text { Narrative Memory*; Attention/ } \\
\text { Executive Function: Tower*, } \\
\text { Auditory Attention, Visual } \\
\text { Attention*); Conners' Continuous } \\
\text { Performance Test-II; Peabody } \\
\text { Picture Vocabulary Test-III* } \\
\text { and WPPSI-R (Block Design, } \\
\text { Vocabulary). }\end{array}$ & $\begin{array}{l}\text { Both EG1 and EG2 (history of neglect) } \\
\text { exhibited significantly lower IQ, attention, } \\
\text { visual memory, language, verbal memory, } \\
\text { learning, planning, problem solving, and } \\
\text { naming scores as compared to the CG. }\end{array}$ \\
\hline $\begin{array}{l}\text { Cicchetti, } \\
\text { Rogosch, } \\
\text { Howe, \& Toth } \\
(2010)\end{array}$ & $\begin{array}{l}N=317 \\
\mathrm{M}=9.17 \text { years } \\
(2.43)\end{array}$ & $\begin{array}{l}\text { CVLT; Peabody Picture } \\
\text { Vocabulary Test-III. }\end{array}$ & $\begin{array}{l}\text { There were no significant between-group } \\
\text { differences in verbal episodic memory. }\end{array}$ \\
\hline $\begin{array}{l}\text { De Bellis et al. } \\
(2010)\end{array}$ & $\begin{array}{l}N=216 \\
\mathrm{M}=10.8 \text { years } \\
(3.5)\end{array}$ & $\begin{array}{l}\text { NEPSY (Face Memory, Narrative } \\
\text { Memory); Rey-Osterrieth } \\
\text { Complex Figure Test; CVLT; CPT- } \\
\text { II; WISC-III or WPPSI-R (Block } \\
\text { Design, Vocabulary). }\end{array}$ & $\begin{array}{l}\text { There were no significant between-group } \\
\text { differences in verbal memory, attention, or } \\
\text { IQ. }\end{array}$ \\
\hline
\end{tabular}

Note. Legend: CVLT = California Verbal Learning Test; CPT-II= Conners' Continuous Performance Test-II; MAS = Memory Assessment Scale; NART = National Adult Reading Test; TMT = Trail Making Test; TOMAL = Test of Memory and Learning; VMI = Beery-Buktenica Developmental Test of Visual-Motor Integration; WAIS-III = Wechsler Adult Intelligence Scale-III; WAIS-R $=$ Wechsler Adult Intelligence Scale, Revised; WISC-III = Wechsler Intelligence Scale for Children-III; WCST = Wisconsin Card Sorting Test; WMS-III = Wechsler Memory Scale, Third Edition; WMS-R = Wechsler Memory Scale, Revised; WPPSI-R = Wechsler Preschool and Primary Scale of Intelligence, Revised.

$\mathrm{EG}=$ experiment group; $\mathrm{CG}=$ control group.

$* p<.05$.

Table 1 presents the main findings of the 17 studies included in this review as to the effects of maltreatment on cognition. Analysis of data suggests that exposure to child maltreatment is associated with cognitive changes in adults and children/teenagers alike. The most widely studied form of maltreatment was sexual abuse, wit zh most samples consisting of adult female subjects. Of the 17 studies analyzed, six (35.3\%) found no statistically significant between-group differences in cognitive functioning: verbal episodic memory, attention, IQ, visual memory, executive function, and verbal comprehension index.

Of the 11 studies carried out in adults, seven $(63.6 \%)$ showed found between-group difference and suggest that children subjected to child maltreatment exhibit impairment of: verbal declarative memory; executive functions, such as problem solving, planning ahead, mental flexibility (set-shifting); the central executive component of working memory; inhibition; information processing speed; and abstract reasoning in adulthood.

Of the six studies that assessed the effects of maltreatment on cognitive functioning in children or adolescents, two (33.3\%) showed no significant between-group differences in cognitive functioning. On the other hand, four $(66.7 \%)$ found that maltreatment is associated with attention deficits, impairment of executive functions such as problem solving, abstract reasoning, and word naming, planning, working memory, inhibition, mental flexibility, memory, visual-spatial function, visual-motor integration and language.

Some studies also analyzed the severity of maltreatment. This variable was associated with lower performance IQ and overall IQ scores (Bremner et al., 1995) and negatively correlated with verbal declarative memory (delayed recall; Bremner et al., 2004). Navalta et al. (2006) found 
Irigaray, T. Q., Pacheco, J. B., Grassi-Oliveira, R., Fonseca, R. P., Leite, J. C. C. \& Kristensen, C. H. (2013). Child Maltreatment and Later Cognitive Functioning: A Systematic Review.

no significant between-group differences in Memory Assessment Scales (MAS) scores or verbal and short-term memory scores. However, the duration of sexual abuse by a closely related perpetrator was strongly associated with all forms of memory impairment (short term: $p=.009$; verbal: $p=.05$; visual: $p=.004$; global: $p=.0003)$. Linear regression analysis indicated that, for each year of abuse, there was a $2.4 \%(S D=.8 \%)$ reduction in short-term memory, a $2.0 \%(S D=1.0 \%)$ reduction in verbal memory, a $1.9 \%(S D$ $=.6 \%)$ reduction in visual memory and a $2.3 \%(S D=.5 \%)$ reduction in global memory scores. On the GO/NO-GO/ STOP attention task, subjects in the experimental group showed greater variability in reaction times - evidence of impaired inhibitory capacity (Navalta et al., 2006).

Exposure to more than one form of maltreatment was assessed by Nolin and Ethier (2007), who investigated the neuropsychological impact of exposure to physical abuse and neglect. Their results suggested that children exposed to both forms of maltreatment (neglect and abuse) performed worse on cognitive function tests than did children subjected to neglect alone.

The studies of Grassi-Oliveira et al. (2008), GrassiOliveira et al. (2011), Lysaker et al. (2001) and Shannon et al. (2011) stand out, as they assessed the impact of maltreatment on clinical samples - subjects with schizophrenia/schizoaffective disorder or major depressive disorder respectively. Overall, clinical samples and those with a history of childhood maltreatment performed poorly on tasks meant to assess cognitive function (executive functions: problem solving, abstract reasoning, planning ahead, mental flexibility, working memory, information processing speed; verbal episodic memory: measures of immediate, delayed, and verbal recall). According to Lysaker et al. (2001) the study design precludes analysis of potential causal relationships between disease and impairment. However, the impairments described in this study are similar to those reported in studies that assessed cognitive function in participants with no psychiatric disorders.

Data analysis showed that most studies found differences between the experiment and control groups on comparison of cognitive function-related variables. Furthermore, the authors sought to control for variables that could interfere with the study phenomenon, whether by matching groups according to these variables or by providing for them as covariates during analysis. Variables regarded as confounders by the studies' authors included IQ, socio-demographic status, age, educational background, substance abuse, psychiatric or neurological disorders, and medication use.

Overall, the confounders most often controlled for in studies were socioeconomic status and IQ. After Bonferroni correction for multiple comparisons, the differences reported by Beers and De Bellis (2002) remained significant only for the attention and executive function (problem solving, abstract reasoning, planning ahead, mental flexibility, working memory, inhibition, word naming) domains. Porter et al. (2005) found significant betweengroup differences in verbal IQ, attention, and memory. After controlling for both IQ and socioeconomic status, no significant differences in cognitive functioning were detectable. Likewise, De Bellis et al. (2009) found that significant between-group differences remained for all measures except visual-spatial function after controlling for IQ.

\section{Discussion}

The findings of this review show a variety of cognitive functions assessed and, consequently, a broad range of neuropsychological instruments used. Although the neurocognitive effects of psychological trauma have been studied for at least three decades, there is still little consensus on which cognitive domains are most affected (Twamley et al., 2009). In the 17 studies included in the review sample, the most commonly studied functions were memory/learning, attention, intelligence and executive functions and. On the one hand, exploration of these domains appears to be a natural development of the emphasis on memory process changes (Goodman et al., 2010) and on the neural structures underlying these processes - as shown in preclinical (Vermetten \& Bremner, 2002), clinical (Kindt, Soeter, \& Vervliet, 2009; Vermetten \& Bremner, 2002; Woon, Sood, \& Hedges, 2010), and translational studies (Ressler \& Mayberg, 2007; Teicher, Tomoda, \& Andersen, 2006). On the other hand, a growing evidence base points to prefrontal structure changes and executive function impairments in association with psychological trauma and PTSD (Daniels et al., 2010; Morey et al., 2009; Weber et al., 2005). Beyond the domain of memory, increasing interest in the role of executive function components in trauma appears to reflect the notion that medial prefrontal structures play a critical role in reducing conditioned fear (Milad \& Quirk, 2002; Shin, Rauch, \& Pitman, 2005), and that dorsolateral prefrontal structures are associated with the executive deficits commonly seen in PTSD (Leskin \& White, 2007).

In their review, Horner and Hamner (2002) reported that cognitive impairment, as diagnosed by neuropsychological testing, occurred in a relatively uniform manner regardless of the stressor event. According to the studies assessed in this review, the cognitive functions most commonly impaired in individuals with PTSD include (a) memory (to a greater extent in terms of immediate retrieval of verbal and visual information; to a lesser extent, in terms of non-immediate retrieval); (b) attention, both verbal and visual; and (c) executive functions, including problem solving (Horner \& Hamner, 2002). In their influential cognitive model of PTSD, Ehlers and Clark (2000) place particular emphasis on errors in interpretation of environmental stimuli, self-monitoring difficulties, and impaired integration of memory content - processes in which executive functions play a role (Mesulan, 2000; 
Royall et al., 2002) and impairment of which appears to be a core symptom of PTSD.

Although there is no consensus definition of executive function and the processing of each of its individual components has yet to be clarified in the literature, it bears noting that the present review found evidence of maltreatment-related impairment of cognitive processes implicated in executive function, such as problem solving, planning, working memory, inhibition, mental flexibility, information processing speed and abstract reasoning. Overall, have suggested that executive function is impaired in combat veterans (Vasterling, Brailey, Constans, \& Sutker, 1998), former prisoners of war (Sutker, Vasterling, Brailey, \& Allain, 1995), or individuals exposed to a variety of stressors, including combat and sexual abuse (Koenen et al., 2001). Furthermore, the brain structures associated with frontal-subcortical circuits, which provide the neuronal substrate for executive function (Heyder, Suchan, \& Daum, 2004; Royall et al., 2002), have been implicated in PTSD (Bremner, 2002; De Bellis, 2005; Yehuda, 2001).

Overall, studies that investigated the effects of child maltreatment on cognitive functioning in adulthood showed impairment in verbal episodic memory, executive function, and working memory. On the other hand, studies of children and adolescents subjected to child maltreatment revealed impairment in attention and executive functions. Some conclusions may be drawn from the findings of the studies analyzed in this review. Firstly, child and adolescence maltreatment has deleterious effects on cognitive function in childhood and adolescence. The findings that indicate this remain significant even after controlling for potential confounders, including IQ, socio-demographic status, medication use, or comorbid psychiatric disorders. Broadly speaking, the main findings of the studies included herein show that subjects exposed to maltreatment (both adults and children) perform poorly on tasks designed to assess verbal episodic memory, working memory, attention, and executive function. Therefore, this study shows that traumatic stressor events occurring in childhood or adolescence pose a risk to both short- and long-term development by inducing cognitive impairment (Margolin, 2005).

Some of the studies analyzed in this review (Bremner et al., 1995; Bremner et al., 2004; Navalta et al., 2006) reported associations between abuse severity and low IQ, poor performance in verbal and visual memory tasks, and impaired attention and executive functions (inhibition). These results clearly show the deleterious effect of prolonged exposure to maltreatment on cognitive functioning; furthermore, they suggest a dire need for studies that take into account type, severity, and duration of abuse.

Exposure to more than one form of maltreatment was analyzed by Nolin and Ethier (2007), who found that children exposed to both neglect and abuse performed worse on cognitive function tests than did children subjected to neglect alone. This suggests that exposure to more than one type of maltreatment may have a worse impact on cognitive functioning, and thus pose a cumulative risk of negative developmental effects (Cicchetti \& Toth, 2005).

In this systematic review, six studies found no association between child maltreatment and changes in cognitive function. One possible explanation for this finding is that these studies may have failed to control for confounders such as age at onset of maltreatment, developmental stage at the time of maltreatment, and amount, intensity, and type of maltreatment (Cicchetti et al., 2010). Other factors, such as sample size and recruitment site, may also have influenced results (Choi et al., 2009; Stein et al., 1999).

De Bellis et al. (2010) suggest that studies of child maltreatment should: (a) use larger samples; (b) use longitudinal and (c) multicenter designs; (d) include clinicians with specialist expertise in developmental assessment and cognitive neuroscience. Stein et al. (1999) maintain that traumatic stressors of different types will necessarily produce different neurocognitive sequelae. Hence, one may infer that the type and intensity of trauma, the gender of the traumatized person and their developmental stage at the time of trauma, and the time elapsed between exposure to the traumatic event and testing may interact and influence the extent of vulnerability to neurocognitive dysfunction.

Analysis of articles for inclusion in this review uncovered certain methodological shortcomings that must be noted. Limitations included: (a) use of several assessment instruments and investigation of more than one aspect of cognition, with no effort toward standardization of the neuropsychological instruments employed in assessment of cognitive function (most studies); (b) small sample size; (c) adult-centered samples (only six studies were carried out on children/teenagers); (d) almost exclusive focus on sexual and physical abuse to the detriment of other forms of maltreatment, including emotional abuse and emotional neglect e; (e) wide variability in study design as far as detection of maltreatment is concerned (data collection techniques ranged from self-reporting to review of case records of social and protection services); (f) the study samples were composed mostly of female participants.

In general, the studies included in this systematic review show that traumatic childhood experiences - such as maltreatment - may cause cognitive changes in adults and children/teenagers alike. In an apparent paradox considering the staggering risk it poses to development, maltreatment in childhood may be the single factor most susceptible to prevention and intervention (De Bellis, 2005). There is a pressing need for further studies on this topic that might contribute to our understanding of the cognitive impairments associated with child maltreatment. Furthermore, the identification of such impairments provides an opportunity for implementation of specific cognitive-behavioral and pharmacological interventions (Brewin, 2006; Friedman, 2005), in order to minimize the negative effects of child maltreatment. 
Irigaray, T. Q., Pacheco, J. B., Grassi-Oliveira, R., Fonseca, R. P., Leite, J. C. C. \& Kristensen, C. H. (2013). Child Maltreatment and Later Cognitive Functioning: A Systematic Review.

\section{References}

Beers, S. R., \& De Bellis, M. D. (2002). Neuropsychological function in children with maltreatment-related posttraumatic stress disorder. American Journal of Psychiatry, 159(3), 483-486.

Bernstein, D. P., Fink, L., Handelsman, L., Foote, J., Lovejoy, M., Wenzel, K., ...Ruggiero, J. (1994). Initial reliability and validity of a new retrospective measure of child abuse and neglect. American Journal of Psychiatry, 151(8), 1132-1136.

Bernstein, D. P., Stein, J. A., Newcomb, M. D., Walker, E., Pogge, D., Ahluvalia, T., ...Zule, W. (2003). Development and validation of a brief screening version of the Childhood Trauma Questionnaire. Child Abuse \& Neglect, 27(2), 169190.

Boden, J. M., Horwood, L. J., \& Fergusson, D. M. (2007). Exposure to childhood sexual and physical abuse and subsequent educational achievement outcomes. Child Abuse \& Neglect, 31(10), 1101-1114.

Bremner, J. D. (1999). Does stress damage the brain? Biological Psychiatry, 45(7), 797-805.

Bremner, J. D. (2002). Does stress damage the brain? Understanding trauma-related disorders from a mind-body perspective. New York: W.W. Norton.

Bremner, J. D., Randall, P., Scott, T. M., Capelli, S., Delaney, R., McCarthy, G., \& Charney, D. S. (1995). Deficits in short-term memory in adult survivors of childhood abuse. Psychiatric Research, 59(1-2), 97-107.

Bremner, J. D., Vermetten, E., Afzal, N., \& Vythilingam, M. (2004). Deficits in verbal declarative memory function in women with childhood sexual abuse-related posttraumatic stress disorder. Journal of Nervous and Mental Disease, 192(10), 643-649.

Bremner, J. D., Vythilingam, M., Vermetten, E., Southwick, S. M., McGlashan, T., Nazeer, A., ...Charney, D. S. (2003). MRI and PET study of deficits in hippocampal structure and function in women with childhood sexual abuse and posttraumatic stress disorder. American Journal of Psychiatry, 160(5), 924-932.

Brewin, C. R. (2006). Implications for clinical evaluation. In J. J. Vasterling \& C. R. Brewin (Eds.), Neuropsychology of PTSD: Biological, cognitive, and clinical perspectives (pp. 271-291). New York: Guilford.

Briere, J. (1997). Psychological assessment of adult posttraumatic states. Washington, DC: American Psychological Association.

Briere, J., \& Elliott, D. M. (2003). Prevalence and psychological sequelae of self-reported childhood physical and sexual abuse in a general population sample of men and women. Child Abuse \& Neglect, 27(10), 1205-1222.

Brito, A. M. M., Zanetta, D. M. T., Mendonça, R. C. V., Barison, S. Z. P., \& Andrade, V. A. G. (2005). Violência doméstica contra crianças e adolescentes: Estudo de um programa de intervenção. Ciência \& Saúde Coletiva, 10(1), 143-149.

Choi, J., Jeong, B., Rohan, M. L., Polcari, A. M., \& Teicher, M. H. (2009). Preliminary evidence for white matter tract abnormalities in young adults exposed to parental verbal abuse. Biological Psychiatry, 65(3), 227-234.

Cicchetti, D., \& Toth, S. L. (2005). Child maltreatment. Annual Review of Clinical Psychology, 1, 409-438.

Cicchetti, D., Rogosch, F. A., Howe, M. L., \& Toth, S. L. (2010). The effects of maltreatment and neuroendocrine regulation on memory performance. Child Development, 81(5), 1504-1519.
Daniels, J. K., McFarlane, A. C., Bluhm, R. L., Moores, K. A., Clark, C. R., Shaw, M. E., ...Lanius, R. A. (2010). Switching between executive and default mode networks in posttraumatic stress disorder: Alterations in functional connectivity. Journal of Psychiatry and Neuroscience, 35(4), 258-266.

De Bellis, M. D. (2005). The psychobiology of neglect. Child Maltreatment, 10(2), 150-172.

De Bellis, M. D., Hooper, S. R., \& Sapia, J. L. (2005). Early trauma exposure and the brain. In J. J. Vasterling \& C. R. Brewin (Eds.), Neuropsychology of PTSD: Biological, cognitive, and clinical perspectives (pp. 153-177). New York: Guilford.

De Bellis, M. D., Hooper, S. R., Spratt, E. G., \& Woolley, D. P. (2009). Neuropsychological findings in childhood neglect and their relationships to pediatric PTSD. Journal of the International Neuropsychological Society, 15(6), 868-878.

De Bellis, M. D., Hooper, S. R., Woolley, D. P., \& Shenk, C. E. (2010). Demographic, maltreatment, and neurobiological correlates of PTSD symptoms in children and adolescents. Journal of Pediatric Psychology, 35(5), 570-577.

Dube, S. R., Felitti, V. J., Dong, M., Chapman, D. P., Giles, W. H., \& Anda, R. F. (2003). Childhood abuse, neglect, and household dysfunction and the risk of illicit drug use: The Adverse Childhood Experiences Study. Pediatrics, 111(3), 564-572.

Eckenrode, J., Laird, M., \& Doris, J. (1993). School performance and disciplinary problems among abused and neglected children. Developmental Psychology, 29(1), 53-62.

Ehlers, A., \& Clark, D. M. (2000). A cognitive model of posttraumatic stress disorder. Behaviour Research and Therapy, 38(4), 319-345.

Faleiros, J. M., Matias, A. S. A., \& Bazon, M. R. (2009). Violência contra crianças na cidade de Ribeirão Preto, São Paulo, Brasil: A prevalência dos maus-tratos calculada com base em informações do setor educacional. Cadernos de Saúde Pública, 25(2), 337-348.

Friedman, M. J. (2005). Pharmacological approaches to cognitive deficits associated with PTSD. In J. J. Vasterling \& C. R. Brewin (Eds.), Neuropsychology of PTSD: Biological, cognitive, and clinical perspectives (pp. 292-325). New York: Guilford.

Gilbert, R., Widom, C. S., Browne, K., Fergusson, D. M., Webb, E., \& Janson, S. (2009). Burden and consequences of child maltreatment in high-income countries. Lancet, 373(9657), 68-81.

Glaser, D. (2000). Child abuse and neglect and the brain- A review. Journal of Child Psychology and Psychiatry, 41(1), 97-116.

Goodman, G. S., Quas, J. A., \& Ogle, C. M. (2010). Child maltreatment and memory. Annual Review of Psychology, $61,325-351$.

Grassi-Oliveira, R., Ashy, M., \& Stein, L. M. (2008). Psychobiology of childhood maltreatment: Effects of allostatic load? Revista Brasileira de Psiquiatria, 30(1), 60-68.

Grassi-Oliveira, R., Gomes, C. F., \& Stein, L. M. (2011). False recognition in women with a history of childhood emotional neglect and diagnose of recurrent major depression. Consciousness and Cognition, 20(4), 1127-1134.

Heyder, K., Suchan, B., \& Daum, I. (2004). Cortico-subcortical contributions to executive control. Acta Psychologica, 115(23), 271-289.

Horner, M. D., \& Hamner, M. B. (2002). Neurocognitive functioning in posttraumatic stress disorder. Neuropsychology Review, 12(1), 15-30. 
Hussey, J. M, Chang, J. J., \& Kotch, J. B. (2006). Child maltreatment in the United States: Prevalence, risk factors, and adolescent health consequences. Pediatrics, 118(3), 933-942.

Johnson, J. G., Cohen, P., Gould, M. S., Kasen, S., Brown, J., \& Brook, J. S. (2002). Childhood adversities, interpersonal difficulties, and risk for suicide attempts during late adolescence and early adulthood. Archives of General Psychiatry, 59(8), 741-749.

Kendall-Tackett, K. A., \& Eckenrode, J. (1996). The effects of neglect on academic achievement and disciplinary problems: A developmental perspective. Child Abuse \& Neglect, 20(3), 161-169.

Kindt, M., Soeter, M., \& Vervliet, B. (2009). Beyond extinction: Erasing human fear responses and preventing the return of fear. Nature Neuroscience, 12(3), 256-258.

Koenen, K. C., Driver, K. L., Oscar-Berman, M., Wolfe, J., Folsom, S., Huang, M. T., \& Schlesinger, L. (2001). Measures of prefrontal system dysfunction in posttraumatic stress disorder. Brain and Cognition, 45(1), 64-78.

Kurtz, P. D., Gaudin, J. M., Wodarski, J. S., \& Howing, P. T. (1993). Maltreatment and the school-aged child: School performance consequences. Child Abuse \& Neglect, 17(5), 581-589.

Lansford, J. E., Dodge, K. A., Pettit, G. S., Bates, J. E., Crozier, J., \& Kaplow, J. (2002). A 12-year prospective study of the long-term eff ects of early child physical maltreatment on psychological, behavioral, and academic problems in adolescence. Archives of Pediatrics \& Adolescent Medicine, 156(8), 824-830.

Leskin, L. P., \& White, P. M. (2007). Attentional networks reveal executive function deficits in posttraumatic stress disorder. Neuropsychology, 21(3), 275-284.

Lysaker, P. H., Meyer, P., Evans, J. D., \& Marks, K. A. (2001). Neurocognitive and symptom correlates of self-reported childhood sexual abuse in schizophrenia spectrum disorders. Annals of Clinical Psychiatry, 13(2), 89-92.

MacMillan, H. L., Fleming, J. E., Trocme, N., Boyle, M. H., Wong, M., Racine, Y. A., ...Offord, D. R. (1997). Prevalence of child physical and sexual abuse in the community. Results from the Ontario Health Supplement. Journal of the American Medical Association, 278(2), 131-135.

Margolin, G. (2005). Children's exposure to violence: Exploring developmental pathways to diverse outcomes. Journal of Interpersonal Violence, 20(1), 72-81.

May-Chahal, C., \& Cawson, P. (2005). Measuring child maltreatment in the United Kingdom: A study of the prevalence of child abuse and neglect. Child Abuse \& Neglect, 29(9), 969-984.

McLeer, S. V., Deblinger, E., Henry, D., \& Orvaschel, H. (1992). Sexually abused children at high risk for post-traumatic stress disorder. Journal of the American Academy of Child and Adolescent Psychiatry, 31, 875-879.

Mesulan, M. M. (2000). Attentional networks, confusional states and neglect syndromes. In M. M. Mesulam (Ed.), Principles of behavioral and cognitive neurology (pp. 174-256). New York: Oxford University Press.

Mezzacappa, E., Kindlon, D., \& Earls, F. (2001). Child abuse and performance task assessments of executive functions in boys. Journal of Child Psychology and Psychiatry, 42(8), 1041-1048.

Milad, M. R., \& Quirk, G. J. (2002). Neurons in medial prefrontal cortex signal memory for fear extinction. Nature, 420(6911), 70-74.
Morey, R. A., Dolcos, F., Petty, C. M., Cooper, D. A., Hayes, J. P., LaBar, K. S., \& McCarthy, G. (2009). The role of traumarelated distractors on neural systems for working memory and emotion processing in posttraumatic stress disorder. Journal of Psychiatric Research, 43(8), 809-817.

Mullen, P. E., Martin, J. L., Anderson, J. C., Romans, S. E., \& Herbison, G. P. (1996). The long-term impact of the physical, emotional, and sexual abuse of children: A community study. Child Abuse \& Neglect, 20(1), 7-21.

Navalta, C. P., Polcari, A., Webster, D. M., Boghossian, A., \& Teicher, M. H. (2006). Effects of childhood sexual abuse on neuropsychological and cognitive function in college women. Journal of Neuropsychiatry \& Clinical Neurosciences, 18(1), 45-53.

Nolin, P., \& Ethier, L. (2007). Using neuropsychological profiles to classify neglected children with or without physical abuse. Child Abuse \& Neglect, 31(6), 631-643.

Porter, C., Lawson, J. S., \& Bigler, E. D. (2005). Neurobehavioral sequelae of child sexual abuse. Child Neuropsychology, 11(2), 203-220.

Pynoos, R. S. (1992). Transtorno de estresse pós-traumático em crianças e adolescentes. In B. D. Garfinkel, G. A. Carlson, \& E. B. Weller (Eds.), Transtornos psiquiátricos na infância e adolescência (pp. 53-65). Porto Alegre, RS: Artes Médicas.

Ressler, K. J., \& Mayberg, H. S. (2007). Targeting abnormal neural circuits in mood and anxiety disorders: From the laboratory to the clinic. Nature Neuroscience, 10(9), 1116-1124.

Rowe, E., \& Eckenrode, J. (1999). The timing of academic difficulties among maltreated and nonmaltreated children. Child Abuse \& Neglect, 23(8), 813-832.

Royall, D. R., Lauterbach, E. C., Cummings, J. L., Reeve, A., Rummans, T. A., Kaufer, D. I., ...Coffey, C. E. (2002). Executive control function: A review of its promise and challenges for clinical research. A report from the Committee on Research of the American Neuropsychiatric Association. Journal of Neuropsychiatry \& Clinical Neurosciences, 14(4), 377-405.

Savitz, J., van der Merwe, L., Stein, D. J., Solms, M., \& Ramesar, R. (2007). Genotype and childhood sexual trauma moderate neurocognitive performance: A possible role for brain-derived neurotrophic factor and apolipoprotein E variants. Biological Psychiatry, 62(5), 391-399.

Shannon, C., Douse, K., McCusker, C., Feeney, L., Barrett, S., \& Mulholland, C. (2011). The association between childhood trauma and memory functioning in schizophrenia. Schizophrenia Bulletin, 37(3), 531-537.

Shin, L. M., Rauch, S. L., \& Pitman, R. K. (2005). Structural and functional anatomy of PTSD: Findings from neuroimaging research. In J. J. Vasterling \& C. R. Brewin (Eds.), Neuropsychology of PTSD: Biological, cognitive, and clinical perspectives (pp. 59-82). New York: Guilford.

Shonk, S. M., \& Cicchetti, D. (2001). Maltreatment, competency deficits, and risk for academic and behavioral maladjustment Developmental Psychology, 37(1), 3-17.

Ska, B., Fonseca, R. P., Scherer, L. C. Oliveira, C. R., Parente, M. A. M. P., \& Joanette, Y. (2009). Mudanças no processamento cognitivo em adultos idosos: Déficits ou estratégias adaptativas? Estudos Interdisciplinares sobre Envelhecimento, 14, 13-24.

Stein, M. B., Hanna, C., Vaerum, V., \& Koverola, C. (1999). Memory functioning in adult women traumatized by childhood sexual abuse. Journal of Traumatic Stress, 12(3), 527-534. 
Irigaray, T. Q., Pacheco, J. B., Grassi-Oliveira, R., Fonseca, R. P., Leite, J. C. C. \& Kristensen, C. H. (2013). Child Maltreatment and Later Cognitive Functioning: A Systematic Review.

Stein, M. B., Koverola, C., Hanna, C., Torchia, M. G., \& McClarty, B. (1997). Hippocampal volume in women victimized by childhood sexual abuse. Psychological Medicine, 27(4), 951-959.

Strathearn, L., Gray, P. H., O'Callaghan, F., \& Wood, D. O. (2001). Childhood neglect and cognitive development in extremely low birth weight infants: A prospective study. Pediatrics, 108(1), 142-151.

Sutker, P. B., Vasterling, J. J., Brailey, K., \& Allain, A. N., Jr. (1995). Memory, attention, and executive deficits in POW survivors: Contributing biological and psychological factors. Neuropsychology, 9(1), 118-125.

Teicher, M. H., Tomoda, A., \& Andersen, S. L. (2006). Neurobiological consequences of early stress and childhood maltreatment: Are results from human and animal studies comparable? Annals of the New York Academy of Sciences, 1071, 313-323.

Twamley, E. W., Allard, C. B., Thorp, S. R., Norman, S. B., Hami Cissell, S., Hughes Berardi, K., ... Stein, M. B. (2009). Cognitive impairment and functioning in PTSD related to intimate partner violence. Journal of the International Neuropsychological Society, 15(6), 879-887.

Vasterling, J. J., Brailey, K., Constans, J. I., \& Sutker, P. B. (1998). Attention and memory dysfunction in posttraumatic stress disorder. Neuropsychology, 12(1), 125-133.

Vermetten, E., \& Bremner, J. D. (2002). Circuits and systems in stress. I. Preclinical studies. Depression and Anxiety, 15(3), 126-147.

Weber, D. L., Clark, C. R., McFarlane, A. C., Moores, K. A., Morris, P., \& Egan, G. F. (2005). Abnormal frontal and parietal activity during working memory updating in posttraumatic stress disorder. Psychiatry Research, 140(1), 27-44.

Weinstein, D., Staffelbach, D., \& Biaggio, M. (2000). Attentiondeficit hyperactivity disorder and posttraumatic stress disorder: Differential diagnosis in childhood sexual abuse. Clinical Psychology Review, 20, 359-378.

Woon, F. L., Sood, S., \& Hedges, D. W. (2010). Hippocampal volume deficits associated with exposure to psychological trauma and posttraumatic stress disorder in adults: A metaanalysis. Progress in Neuro-Psychopharmacology \& Biological Psychiatry, 34(7), 1181-1188.

Yehuda, R. (2001). Biology of posttraumatic stress disorder. Journal of Clinical Psychiatry, 62(Suppl. 17), 41-46.

Yehuda, R., Stavitsky, K., Tischler, L., Golier, J. A., \& Harvey, P. D. (2005). Learning and memory in aging trauma survivors with PTSD. In J. J. Vasterling \& C. R. Brewin (Eds.), Neuropsychology of PTSD: Biological, cognitive, and clinical perspectives (pp. 208-229). New York: Guilford. 